\section{Lessons in Leadership}

\section{MAY KHADEM}

\section{Abstract}

As individual health professionals and institutions struggle to address health disparities worldwide, it becomes increasingly apparent that the answers are exceedingly complex and require a complete change in thinking, orientation, and behavior that includes ourselves. This paper is about a personal journey of learning about leadership that reveals widely shared false assumptions that have led many off course in addressing the challenges in the fight against blindness as well as other public health concerns.

\section{Résumé}

$\mathrm{Au}$ fur et à mesure que les professionnels de la santé et les institutions s'efforcent de remédier aux inégalités en matière de santé dans le monde, il devient de plus en plus clair que les réponses sont extrêmement complexes et exigent un changement radical de nos façons de penser, de nos orientations et de nos comportements. Le présent document décrit un cheminement personnel d'apprentissage du leadership qui dévoile de fausses hypothèses largement répandues qui ont mené bien des gens à faire fausse route en tentant de relever les défis qui se posent dans la lutte contre la cécité.

\section{Resumen}

A medida que individuos profesionales de la salud e instituciones luchan por atender disparidades de salud alrededor del mundo, se vuelve cada vez más aparente que las respuestas son excedentemente más complejas y requieren un cambio completo de pensamiento, orientación y comportamiento que nos incluyen. Este ensayo es sobre un viaje personal de aprendizaje acerca del liderazgo el cual revela suposiciones falsas ampliamente compartidas que han llevado a muchos fuera de rumbo al atender los desafíos en la lucha contra la ceguera.

Despite the trillions of dollars spent on addressing health challenges in the world over the past several decades, the problems of extreme poverty, hunger, disease, and social injustice remain dire. The world has failed to address the well-recognized major global issues of our time-climate change, pollution, economic failure, extreme inequality, homelessness, and violence, among many others.

According to the World Economic Forum's 2015 "Survey on the Global Agenda," a surprising eighty-six percent of respondents perceived a global crisis in leadership. The most distrusted were religious leaders, followed by leaders in government, business, and non-governmental agencies (14-16). Even heads of charitable organizations were suspect, with only half of the respondents showing confidence in them. Among the key ingredients identified for successful leadership were morality, prioritization of social justice, empathy, collaboration, courage, a global perspective, long-term planning, and good communication skills (14-16). Ironically, when the World Health Organization (WHO) evaluated its initiative "Health for All 
by the Year 2000," ${ }^{1}$ a global plan to provide primary healthcare to all the world's citizens, the initiative itself was deemed a failure - not because of lack of resources or know-how, but for lack of "moral leadership" (WHO, "Report" 7).

When I started my career as a young ophthalmologist, I was very idealistic. I knew there was a lot of unnecessary blindness in the world, and I wanted to be part of the solution. At the time - in the early 1990s-it was estimated that there were 45 million blind people and another 200 million with low vision (WHO, "Vision 2020" 3). These numbers have not changed significantly over the past few decades (WHO, "Blindness: Vision 2020”). Most visual impairment-almost eighty percent - is avoidable; that is, it is either curable or preventable (WHO, "Blindness and Vision Impairment").

"What an opportunity," I thought. I presumed that surely those dedicated to the fight against blindness should be able to address its leading causes worldwide. Since half of blindness was due to cataracts and a simple operation could restore sight, at least this particular cause could be easily treated. The global blindness prevention community had knowledge and skills, and all that was needed was to mobilize these resources. Since most of the people blinded by cataracts lived in poor and middle-income countries, the

1 For more details, please see the World Health Organization's "Declaration of Alma-Ata." International Conference on Primary Health Care, 1978. solution seemed very simple to mego to these countries, find the blind people, and cure them!

Well, I have since learned that all is not so simple. In fact, responding to such a problem is exceedingly complicated. As it turns out, it is not sufficient that individuals be treated; rather, whole systems must simultaneously be transformed. And to treat problems at a systemic level, one needs unity of vision and purpose. In short, the key to bringing about a solution is leadership. To support this argument, I would like to share my journey of learning about leadership over more than thirty years of work, spanning thirteen projects in ten different countries.

\section{EMBARKING ON A JOURNEY}

I started my career working for the International Eye Foundation in a project funded by $\mathrm{USAID}^{2}$ in the Caribbean island nation of Grenada, a tiny country less than ten by twenty miles with a population of 100,000 . After the United States invaded the country in the mid-1980s, the local infrastructure had to be rebuilt. The project in which I was involved sought to create and make sustainable a national eye care system from the ground up. Almost ninety percent of

2 United States Agency for International Development, an independent agency of the US federal government that is primarily responsible for administering civilian foreign aid and development assistance. 
blindness and visual impairment in the world occurs in low and middle-income countries where fewer resources are available, and Grenada was such a country (WHO, "Vision 2020" 3). There, I learned that it is possible to transform an entire healthcare system and make it sustainable. Grenada went from being a country with no modern eye care to one in which comprehensive eye services became availableand are still functioning to this day. At the time, I wasn't really sure what the essential prerequisites for success were, but the experience changed the course of my life.

When I returned to the United States almost three years later, I joined an ophthalmology practice in Chicago, but my heart was still taken with health development in areas of need. And so, for the next two years, together with some colleagues, I made short visits to the Turks and Caicos Islands and to Guyana to offer services where resources were lacking.

Turks and Caicos was particularly underserved: eye care, and eye surgery in particular, were only available intermittently through the International Eye Foundation (the sponsor of my work in Grenada), ${ }^{3}$ which would recruit ophthalmologists to travel there for surgery every six months or so. This method of ministering to eye care in Turks and Caicos had been going on for years; the country was totally dependent on foreign charity.

3 Details regarding the work of this foundation can be found on its website: www.iefusa.org.
While the inhabitants accepted it, they understandably resented it. We had never before witnessed such distrust of foreigners, sometimes even manifested as open hostility. It surprised us, but it also forced us to re-examine our assumptions. We learned our first important lesson there.

\section{Lesson 1: Charity is not a long-term solution. It has a role in times of cri- sis and for disaster relief, but to use it long-term is harmful. It disempowers local resources, creates dependency, and strips people of their dignity.}

I have come to believe that in many cases, sustained charity is like giving sugar to a diabetic who is having a hypoglycemic episode. It may be life-saving in the short term, but it exacerbates the illness if continued long-term. When we reflected on our learning with other like-minded colleagues, we realized that we shared many experiences. We tried to imagine what a Bahá'í-inspired effort might look like. How would the approach to health development be different if it were informed by the vision of the oneness of humanity and the imperative of social justice? In 1991, we had the opportunity to make a trip to Albania just after the government had transitioned from a dictatorship that had kept it isolated from the rest of the world for over fifty years. We assembled a group of three physicians in different specialties (a pediatrician, a dermatologist, and an ophthalmologist), together with a teacher, a 
nutritionist, and a businessman, and went on a fact-finding mission to Albania, hoping to find opportunities for service where we might experiment with a different model. Meanwhile, one of the colleagues we were consulting with had been a volunteer in Honduras at Hospital Bayan, also a Bahá'í-inspired initiative, and encouraged us to collaborate more closely with that institution. We had also been encouraged by then-member of the Universal House of Justice Dr. David Ruhe to collaborate with the Bahá'í community in Guyana in their efforts to provide health services for the Amerindian population in the Rupununi region of Guyana. As these opportunities developed into projects, the need to formalize our efforts resulted in the founding in 1992 of Health for Humanity, a Bahá'í-inspired health development organization.

We began by applying for grants and undertook efforts to address a variety of health concerns, including the leading causes of blindness. Based on our past experiences and through study of others' learnings, ${ }^{4}$ we appreciated the fact that we had to focus on building local capacity rather than creating dependency on charity. The problem was that we really did not know how to go about doing this. We did what most organizations working

4 In particular, we read messages on social and economic development written by the Universal House of Justice in 1983 and 1993, as well as guidance from the Office of Social and Economic Development at the Bahá'í World Centre. in this space did: a combination of charity and technical assistance. At the time, "capacity-building" was the new buzzword among organizations working in development. It sounded great, but in reality, it was reduced to "technical transfer of knowledge,"still an improvement over the traditional model, whereby visiting experts would provide all the care.

One of Health for Humanity's initiatives had developed into a ten-year project $^{5}$ to help develop eye services in Albania, which, due to its fifty-year isolation, still had services and institutions pre-dating World War II. Through this project, we got busy providing training by sending volunteers to Albania to offer it locally and by sending the local ophthalmologists abroad for more specialized versions. We equipped six eye centers (Tirana, Vlorë, Peshkopi, Shkodër, Korçë, and Elbasan) so that the entire country would have access to eye care services. We also helped to develop a resident training program at the University Eye Hospital in Tirana.

Throughout the project, we noticed problems: some equipment ended up in places we did not intend, some went missing, and local decision-making favored nepotism and short-term agendas. If we were to bring about meaningful transformation, something was missing. It seemed to us an ethical framework that all could agree to might protect the project from

5 Funded mostly by the Open Society Institute (www.opensocietyfoundations. org), as well as a number of smaller donors. 
these problems, but at the time, we did not know how to achieve this. This is when we learned our next important lesson.

\section{Lesson 2: "Capacity-building" is not just technical transfer of knowledge.}

Halfway through the project, we came across the work of Dr. Eloy Anello and the training in "moral leadership" he developed at Nur University, which he had founded in rural Bolivia. ${ }^{6}$ The training he had instigated was structured to help participants explore their assumptions about leadership, human nature, and dysfunctional ways of thinking that interfere with meaningful progress. Once participants develop these insights, they are assisted in embracing those particular ethical principles that will become a foundation for their work. We all felt this conceptual framework might help us. Consequently, with the help of Dr. Anello (and of his colleagues), ${ }^{7}$ we began to introduce this training into the Albania Eye Project and into a new project we had just undertaken to combat river blindness in Cameroon.

The participants' response to this training was very enthusiastic, even quite moving. As a result, we became convinced that this framework for training would be a helpful addition to

6 For details, please visit www.nur.edu.

7 We are greatly indebted to Charles Howard and John Kepner for their dedicated assistance with this training for the staff in Chicago and for projects in Albania, Cameroon, Mongolia, and Argentina. our program. Although several projects received this training, we had to face the fact that we did not have an effective way to measure its impact or a means whereby we could incorporate it in a systematic way. Our work in this arena was thus a bit haphazard. We really did not have a deep insight into its transformative power until ten years later, when we did an evaluation of the Albania Eye Project at its termination, reviewing the work at the six eye centers and interviewing doctors, nurses, residents, and patients to understand the changes that had occurred.

The first thing we noticed was that the doctors we had trained had become quite prosperous, with beautiful homes and luxurious lifestyles. Eye services were available throughout the country, and the ophthalmologists were well-trained. Albanians could receive quality eye care at centers accessible to them, and the cataract surgery rate had increased more than twentyfold. Some patients were even coming from nearby Kosovo and Macedonia for treatment. Naturally, we deemed all this to be a propitious result.

But we also learned about another outcome that was, instead, very disturbing. Those receiving this care were the same people who used to get it in nearby countries, such as Greece or Italy. In other words, those who could afford the services were the ones who had access. However, the people who could not afford to pay - the very populace we were most concerned about-were still not receiving care. The problem of avoidable blindness, 
while perhaps somewhat less urgent, was still very much a problem!

Then, in the course of interviewing the staff we had worked with, we had a breakthrough. At the end of every interview, we would ask if they wished to share anything we had not specifically asked about. The head nurse told us:

The leadership training changed my life; it was the best part of the project... You gave the nurses value. It helped us to appreciate ourselves ... After that, I changed my style of communication with those under me. They saw a difference in me and they liked it. It changed them too. They work differently now. Since I changed my behavior with my subordinates, they changed their behavior with each other and with the patients. It was a new experience.... The way we organize our work changed completely .... We never used to prepare the patients for surgery. We never said anything to them. We talk to patients now. We explain everything and answer their questions. We have a new relationship with each other and with the patients. Even the doctors are happier. We have a new vision now . . . and it is growing as we learn more... (Health for Humanity)

He told us he had provided the moral leadership training for his staff and he even took the initiative of arranging its incorporation into the nursing school curriculum.

We were so excited to learn about the training's impact that we re-interviewed the attending doctors and residents. One former resident told us:

The training completely changed the way we worked. Before, we didn't even know each other's names and everyone was competitive and private with information. After, we saw that it is better for us to help each other and to share information. We were much happier after and learned more. (Health for Humanity)

However, a senior doctor summed up the sentiments of his colleagues by saying, "It was like a good movie. It was great at the time, but when it was over, it was over" (Health for Humanity). Since the nurses, the ones with the least agency in the healthcare hierarchy, were most impacted by the training, and the senior doctors the least, we concluded that the impact was inversely proportional to the degree of agency people had. The residents felt the impact, though to a lesser degree than the nurses. The senior doctors only recalled a pleasant memory, but it did not change their behavior.

What we had witnessed seemed to be a powerful way to mobilize the talents of the entire workforce. We came to believe that if this kind of training were intimately woven into all aspects of medical and surgical training, it could help create a shared 
ethical/moral framework that all would be more likely to honor. Clearly, without such a framework to guide decision-making, healthcare workers' technical skills and knowledge would not necessarily benefit their community. In some instances, they might even cause harm if used for personal gain at the expense of patients' welfare. And so it was that we encountered the next lesson in this organic process of learning about building capacity.

\section{Lesson 3: True capacity-building has an indispensable spiritual dimension.}

Throughout this period, Health for Humanity was collaborating with WHO and with the International Agency for the Prevention of Blindness $(\mathrm{IAPB})^{8}$ and sharing learning with other non-governmental organizations working in this area. We met annually and reviewed progress toward the goal of an initiative called "Vision 2020: The Right to Sight," a global plan for the elimination of avoidable blindness by the year $2020 .^{9}$

We were curious about the experience of other organizations, so we sent out a survey to the institutional members of IAPB. At the time, IAPB had ninety-four institutional members, eighty of which were non-governmental organizations, including our own

8 A multilateral organization that collaborates with WHO to oversee and coordinate efforts to eliminate avoidable blindness.

9 https://www.who.int/blindness/ partnerships/vision2020/en/.
Health for Humanity. The survey was sent out to 147 individuals. Of these, sixty-one responded, a $41 \%$ return. The survey results showed that of the total respondents, $93 \%$ felt that moral values were essential to their success; $83 \%$ said effective leadership is a significant challenge for them; $66 \%$ stated that technical training failed to deliver the desired results; $54 \%$ were having significant problems with honesty and trustworthiness; and $32 \%$ said their projects were struggling or not effective at all. Almost all stated that some equipment or funds were diverted to unintended uses in their projects. When asked to rate the ingredients for success, $74 \%$ rated moral values and ethical behavior as the most important and surgical skill and academic knowledge as the least important! When asked to prioritize ingredients for success, the top three were strong core values, service orientation, and honesty. These respondents were the global leaders in their field and, to our amazement, they were forthrightly acknowledging that moral values are indispensable to success in addressing public health challenges!

Clearly, what we were experiencing was shared among other organizations working in health development, and very likely was common in international development in general. When we shared the survey results with the IAPB member institutions, we were invited to offer the leadership training to these organizations at the agency's next quadrennial General Assembly, in Argentina in 2008. The anecdotal stories we heard, together with the 
survey results and the unexpected interest from member organizations and from multilateral agencies, convinced us that there is a great need for this kind of training. We now had the objective evidence.

\section{Lesson 4: There is growing consensus among leaders in health development} that without the moral/ethical dimension, development efforts will not succeed.

Meanwhile, just as the Albania project ended, Health for Humanity received funding to carry out a more modest project to train cataract surgeons in Ulaanbaatar, Mongolia. We were increasingly convinced that values-based training had to be intimately integrated into the project so we tried to weave it into all activities. We used the materials developed by Dr. Anello and translated the manual into Mongolian.

At the time, Mongolia's healthcare system had a deeply entrenched authoritarian style of leadership. One person made all the decisions, and everyone else deferred. Nevertheless, we were able to convince the director of the eye department that the training would be helpful to everyone, including her. She gave her blessing and even participated, but it was not easy for her.

After decades-maybe even centuries-of passivity when it came to expressing individual opinions or problem-solving, it was very hard to engage the doctors, and very hard for the boss to share authority. The resistance we felt made us question whether change, let alone transformation, was even possible. However, we reminded ourselves that it was a process, perhaps slow in the beginning, but gradually transformative as people found their voice and began to claim their agency.

We saw evidence of this change two years later when one of the doctors from Mongolia shared the following comments in her presentation at the 2008 IAPB General Assembly:

This training was totally different from others, as we had had only technical assistance from different NGOs. We always talked about academic knowledge [and] clinical and surgical training, but the importance of changing attitudes and behaviors in order to achieve something had not been considered. So, the training made many people think about who we are, what we are doing, and where we want to be ... I think the most important impact of the training was that people started to express their views. Before, it was rare to hear anyone share what they truly felt in the larger group. There was a fear to talk about the real situation. But after the training, we felt like we got new eyes to see things around us. Now at the different meetings, those who participated in the trainings are not afraid to express how they really feel ... Now, we make decisions through consultation within the group 
and try to include all the doctors ... After the second training, ten ophthalmologists from different hospitals in Ulaanbaatar decided to meet regularly to solve problems and make decisions ....

We were thrilled. They had learned about consultation! This one capacity was by far the most vital tool for learning and problem-solving. Now they were unstoppable, and we had learned another lesson regarding the training program.

\section{Lesson 5: Consultation is the most} powerful means for continuous learning and improvement.

Our greatest confirmation about the power of consultation in this organic process came from Mongolia's State Secretary for Health, Byambaagiin Batsereedene. "I remember how bad the conditions used to be, and now the eye department is a modern department with high quality services," she said. "However, it is not just the technical improvement that is noticeable," she continued. "There is something else I have not seen before. The doctors treat the patients differently .... The ophthalmologists . . .changed .... They have a very good relationship with the patients and with each other and have now become a model department, not only for the hospital, but for all of Mongolia. I want to see this spread."

There was no longer any doubt. If we wanted to have a lasting impact, we had to incorporate this kind of training in our development efforts. However, we were still experimenting. We had not yet standardized the training. But we had learned that a spiritual framework, when combined with the capacity for consultation, becomes a powerful force for change and transformation.

\section{Lesson 6: The outcome of a spir- itual framework applied through consultation is measurable systemic transformation.}

When work is informed by spiritual principles and learning is applied through consultation, the resulting change is apparent in both quantifiable material outcomes and in qualitative transformation of relationships. The resulting ripple effects can be far-reaching.

As the Mongolia project was winding down, we were recruited to assist with leadership training for WHO's Good Governance for Medicines Programme, an initiative to fight corruption in the pharmaceutical sector. ${ }^{10}$ Dr. Anello was already involved in this project, and the invitation gave me the opportunity to work more closely with him over the next year and a half. We collaborated on rewriting and expanding the training manual he had developed. We worked together to develop training materials first for representatives of Ministries of Health from

10 An interesting overview of this program can be found at www.who.int/ healthsystems/topics/financing/healthreport/25GGM.pdf. 
the Eastern Mediterranean region convening in Jordan, and later for representatives from all over the world convening in Geneva.

During this period, Dr. Anello expressed the desire to expand on the work we had been doing and to collaborate with me and with author Juanita (Joan) Hernandez on publishing his book in English. Unfortunately, his health did not permit it at the time, but Transformative Leadership: Developing the Hidden Dimension was published some five years later, in 2014. A companion workbook Transformative Leadership: Mastering the Hidden Dimension, was published in 2017. The book has also been translated into and published in Chinese.

In 2010, my family had the privilege of moving to China-a country with the greatest burden of blindness in the world. While modern eye care is available in the big cities, it is almost nonexistent in the rural areas. We formed another NGO in China called "Vision in Practice" (or "Aikai" in Chinese). ${ }^{11}$ Under the auspices of this organization, we were fortunate to obtain the assistance of a hospital

11 Vision in Practice was founded in 2011 in partnership with Jeff Parker, an American journalist who co-founded a journal for ophthalmologists in China called Ophthalmology World Report. Through his work, he had become familiar with the Aravind model and had already started to help Chinese ophthalmologists obtain surgical training there. Together, we were able to expand these training opportunities. that has set the global standard for high-quality affordable eye care, Aravind Eye Hospital in India. ${ }^{12}$

Aravind sees more patients, does more surgery, and trains more ophthalmologists than any other hospital in the world. All patients receive stateof-the-art eye care, regardless of their ability to pay. Most of the care is either entirely free or subsidized. Even so, the hospital has a very solid profit margin. Harvard Business School spread the hospital's fame through a case study it published in 1993 (Rangan). Since then, numerous articles have been written about the miracle of Aravind-a hospital that has been instrumental in dramatically reducing the prevalence of blindness in India.

I had the privilege of spending a month there in order to learn how the hospital achieves these amazing outcomes, and I was pleased to see that the magic is not just the efficiency and standardization that so many focus on in their reports about the institution. There is something else crucial going on.

When a patient enters the hospital, regardless of who that patient is or how the patient is dressed, he or she is greeted with a deferential bow and accompanied to receive care. On every floor of the hospital there are signs with quotations from the founder, Dr. Venkataswamy, about service: "Work is worship"; "I pray to be a better instrument, a receptacle for the divine force"; "When we take care of our patients,

12 For details, please visit www.aravind.org/. 
it is ourselves we are helping. It is ourselves we are healing"; "If work is approached from a spiritual perspective, then it becomes divine work"; and many similar axioms. On every floor there is a prayer room, and arching over the door are symbols of all the world religions. In other words, the hospital has managed to institutionalize a spiritual framework, and, what is more important, they have provided ample evidence that it works.

Partnering with this amazing institution was a great opportunity. With Aravind's help, we were able to send some eighty Chinese ophthalmologists for surgical training in India. We helped six hospitals to be mentored by Aravind, and we worked intensively with two of them to transform their services.

A good example of our efforts' impact on an individual level was demonstrated by one of our associates who worked closely with us on the eye projects in China. After our work together ended, she started working for a financial institution. She told us that her job was very stressful and pressured her to compromise her principles. When she refused to do this, she was isolated and even mocked. Those around her were enjoying all kinds of "perks" while she stayed on the sidelines, just carrying out her responsibilities. However, within a year, her entire team was fired and the department restructured because of its questionable practices. She was one of only two people who survived the upheaval. She told us, "Being honest was easy at first, but when everyone else was compromising and putting pressure on me, it was stressful. But I remembered our training and the importance of values. I knew what I had to do.”

An example of the effect of utilizing the tool of consultation in conjunction with the virtue of humility and cooperation at the institutional level can be found in one of the rural hospitals we worked with to raise the standard of eye care which required a painful process of putting the patient's needs first by re-examining assumptions about the doctor-patient relationship. Raising the capacity of all the staff members meant that a spirit of collaboration and mutual aid had to replace the competitive environment. These were difficult changes. However, within two years, a surgical training center was established, all patients began receiving comprehensive eye services-including surgery if needed-regardless of their ability to pay, and the surgical volume more than doubled. The staff told us that they now have guidelines to help them with difficult decisions. They have changed many of their policies that were oppressive or self-serving, such as arbitrary rules unrelated to patient care, accepting gifts for favors, prioritizing wealthy patients, and the like. The chief surgeon told us:

We see things so differently now. When we live by the moral values, we feel more confident. As a result of the training, we feel the strength to overcome any kind of problem. We learned how to work as real doctors, how to 
create a team that is service-aimed, how to encourage each other to keep learning and believe in ourselves. When we improve, it makes us happy. Even when it's difficult, we can make wiser choices than before. (Personal Correspondence)

\section{Lesson 7: True leadership is servitude.}

So far, we have talked about lessons learned about leadership, but not much about the substance of the training. The training we employ is inspired by the Bahá'í teachings. The term "leadership" is probably not the best description. Searching the Bahá'í Writings to gain a deeper understanding of what leadership means in a spiritual context, one will find countless allusions to two somewhat antithetical discourses. On the one hand, there are plentiful passages referring to the desire for leadership as a characteristic of those who are attracted to the desire for power. For example, Baháu'lláh notes how religious leaders of the past have misled their followers by the desire to retain their positions: "Leaders of religion, in every age, have hindered their people from attaining the shores of eternal salvation, inasmuch as they held the reins of authority in their mighty grasp. Some for the lust of leadership, others through want of knowledge and understanding, have been the cause of the deprivation of the people" (Kitábi-Íqán 15).

On the other hand, there are quite as many passages discussing the necessity for humankind at every level to exhibit and maintain virtuous leadership and guidance. For while service to humankind is the hallmark of the Bahá'í teachings, everyone is, at some level, both a servant and a leader, a student and a teacher. Nowhere is this dual function more evident than in the guidance of the current Five Year plans of the Universal House of Justice in which a culture of learning is characterized by a process where everyone is striving to understand the nature of true servitude, while simultaneously accompanying and tutoring others: "The first quality for leadership, both among individuals and Assemblies, is the capacity to use the energy and competence that exists in the rank and file of its followers" (Shoghi Effendi, quoted in Building Momentum 16).

Of course, 'Abdu'l-Bahá, whose very title, meaning "Servant of Bahá" (Bahá'u’lláh), embodies service, exemplifies perfectly the synthesis of leadership and servitude. On the one hand He forthrightly asserts His station as Center of the Covenant and head of the Bahá'í Faith. And yet He describes this leadership position in terms of a servitude to Bahá'u’lláh:

My name is 'Abdu'l-Bahá, my identity is 'Abdu'l-Bahá, my qualification is 'Abdu'l-Bahá, my reality is 'Abdu'l-Bahá, my praise is 'Abdu'l-Bahá. Thraldom to the Blessed Perfection is my glorious and refulgent diadem; and servitude to all the human race is my 
perpetual religion ... No name, no title, no mention, no commendation hath he nor will ever have except 'Abdu'l-Bahá. This is my longing. This is my supreme apex. This is my greatest yearning. This is my eternal life. This is my everlasting glory! (Tablets 429)

In fact, 'Abdu'l-Bahá equates servitude with leadership:

This is not servitude but sovereignty, and this is not service but chieftainship and greatness! This is the garment of everlasting glory with which thou hast clothed thyself, and this is the rose of eternal exaltation with which thou hast adorned thy head. It is said in the New Testament: "Whosoever will be chief among you, let him be your servant." (Tablets 510)

What we are talking about, then, is transformative servitude - a process of personal transformation and service to the community. Therefore, in the training, we help participants identify the challenges with which they are struggling. They then examine the assumptions underlying those challenges. These often have to do with preconceptions of human nature, self-serving habits of thinking, expectations about leadership, and definitions of success.

Once they have examined these assumptions based on scientific evidence and universal moral values found within their own spiritual heritage, they can recognize the flaws in their thinking. They come to realize that the greatest challenge they face is their own personal journey of transformation. They come to realize how indispensable service is in that journey. They are then ready to embrace spiritually informed guidelines with which to construct a conceptual framework for their work. Then, when making difficult decisions or in times of crisis, that principle-based framework can guide them to make the right choices, instead of resorting to previous self-serving habits of thinking.

My own most important learning from this entire journey is that at the heart of servitude is a spiritual journey of personal and collective transformation, for it is only through service that we can transform ourselves, our communities, and ultimately our world.

\section{Works Cited}

'Abdu'l-Bahá. Tablets of 'Abdu'l-Bahá. Bahá'í Publishing Committee, 1909.

Anello, Eloy, Joan Hernandez, and May Khadem. Transformative Leadership: Developing the Hidden Dimension. Harmony Equity Press, 2014.

Batsereedene, Byambaagiin. Personal interview. March 2007.

Health for Humanity Participants. Personal interviews. 
Hernandez, Joan, and May Khadem. Transformative Leadership: Mastering the Hidden Dimension. Harmony Equity Press, 2017.

Personal Correspondence. Received by May Khadem.

Rangan, Kasturi V. The Aravind Eye Hospital, Madurai, India: In Service for Sight. Rev. ed., Harvard Business School, 2009.

The Universal House of Justice. Message to the Bahá'ís of the World, dated 20 October 1983.

"Bahá'i Social Action and Economic Development: Prospects for the Future." 16 September 1993.

Untitled Presentation. Equity and Excellence in Eye Care, International Agency for the Prevention of Blindness Eighth General Assembly, 2008, Buenos Aires, Argentina.

World Economic Forum. "Outlook on the Global Agenda 2015." reports.weforum.org/outlook-global-agenda-2015/wp-content/blogs.dir/59/mp/ files/pages/files/outlook-2015-a4-downloadable.pdf.

World Health Organization (WHO). "Blindness and Vision Impairment." 11 Oct. 2018. www.who.int/news-room/fact-sheets/detail/blindness-andvisual-impairment.

- "Blindness: Vision 2020-The Global Initiative for the Elimination of Avoidable Blindness, Fact sheet $\mathrm{N}^{\circ}$ 213." www.who.int/mediacentre/factsheets/fs213/en/.

"Declaration of Alma-Ata." International Conference on Primary Health Care, 6-12 Sep. 1978, Alma-Ata, USSR. www.who.int/publications/ almaata_declaration_en.pdf?ua $=1$.

- "Report on Technical Discussions: Recommendations and Main Conclusions." Forty-first Assembly on World Health, May 1988, Geneva, Switzerland.

- "Vision 2020: The Right to Sight: Global Initiative for the Elimination of Avoidable Blindness, Action Plan 2006-2011." 2007. www.who.int/ iris/handle/10665/43754. 